\title{
Activation of NLRP3 inflammasome enhances the proliferation and migration of A549 lung cancer cells
}

\author{
YANLI WANG ${ }^{*}$, HUI KONG ${ }^{*}$, XIAONING ZENG, WENRUI LIU, ZAILIANG WANG, \\ XIAOPEI YAN, HONG WANG and WEIPING XIE \\ Department of Respiratory Medicine, The First Affiliated Hospital \\ of Nanjing Medical University, Nanjing, Jiangsu 210029, P.R. China
}

Received July 30, 2015; Accepted November 24, 2015

DOI: $10.3892 /$ or.2016.4569

\begin{abstract}
Lung cancer is the leading cause of cancer death, and it is widely accepted that chronic inflammation is an important risk for the development of lung cancer. Now, it is recognized that the nucleotide-binding and oligomerization domain (NOD) like receptors (NLRs)-containing inflammasomes are involved in cancer-related inflammation. This study was designed to investigate the effects of NLR family pyrin domain containing protein 3 (NLRP3) inflammasome on the proliferation and migration of lung adenocarcinoma cell line A549. Using 5-ethynyl-2'-deoxyuridine (EdU) incorporation assay, scratch assay, and Transwell migration assay, we showed that activation of the NLRP3 inflammasome by LPS+ATP enhanced the proliferation and migration of A549 cells. Western blot analysis showed that activation of phosphorylation of Akt, ERK1/2, CREB and the expression of Snail increased, while the expression of E-cadherin decreased after the activation of NLRP3 inflammasome. Moreover, these effects were inhibited by the following treatments: i) downregulating the expression of NLRP3 by short hairpin RNA (shRNA) interference, ii) inhibiting the activation of NLRP3 inflammasome with a caspase-1 inhibitor, iii) blocking the interleukin-1 $\beta$ (IL-1 $\beta$ ) and IL-18 signal transduction with IL-1 receptor antagonist (IL-1Ra) and IL-18 binding protein (IL-18BP). Collectively, these results indicate that NLRP3 inflammasome plays a vital role in regulating the proliferation and migration of A549 cells and it might be a potential target for the treatment of lung cancer.
\end{abstract}

Correspondence to: Dr Hong Wang or Dr Weiping Xie, Department of Respiratory Medicine, The First Affiliated Hospital of Nanjing Medical University, 300 Guangzhou Road, Nanjing, Jiangsu 210029, P.R. China

E-mail: hongwang@njmu.edu.cn

E-mail:wpxie@njmu.edu.cn

*Contributed equally

Key words: NLRP3 inflammasome, proliferation, migration, lung cancer

\section{Introduction}

Lung cancer is the leading cause of cancer death worldwide. Only $16.6 \%$ of lung cancer patients live 5 years or more after diagnosis (1). In addition to chemotherapy, radiotherapy, and molecular targeted therapy, adjuvant therapies targeting the tumor microenvironment have received a great deal of attention in recent years (2). The inflammatory milieu comprises infiltrated immune cells, cytokines, chemokines, and growth factors, which contribute to tumor proliferation, angiogenesis, metastasis, and chemoresistance (3). Increasing evidence emphasizes that chronic inflammation is crucial for the progression of a tumor (4). Thus, cancer-related inflammation has been recognized as the 'seventh hallmark of cancer' (5).

Inflammasome, an intracellular multi-protein complex, switches on the inflammatory response of tissues to various danger signals. Among the inflammasomes, NLRP3 inflammasome is the most characterized activated by a diverse range of 'danger signals'. It is formed by the assembly of NOD-like receptor NLRP3, adaptor protein apoptosis-associated specklike protein containing a caspase recruitment domain (ASC), and pro-caspase-1. Once activated, NLRP3 inflammasome triggers the proteolytic processing of pro-caspase- 1 into its active form, caspase-1 (p10 or p20), which subsequently cleaves pro-IL-1 $\beta$ and pro-IL-18 to mature bioactive forms. It has been well documented that two signals are required for the formation and activation of NLRP3 inflammasome. Firstly, pathogen-associated molecular patterns (PAMPs) or danger-associated molecular patterns (DAMPs) including viruses, bacteria, or lipopolysaccharide (LPS), prime the expressions of NLRP3, pro-IL-1 $\beta$ and pro-IL-18. Then, a second stimulus such as adenosine 5'-triphosphate (ATP), silica or monosodium urate (MSU) activates the NLRP3 inflammasome (6).

Mounting evidence indicates that NLRP3 inflammasome plays an important role in the development and progression of gastrointestinal cancer, skin cancer, breast cancer and hepatocellular carcinoma (7). However, the effects of NLRP3 inflammasome on the progression of various cancers are complex. For instance, overexpressed and constitutively activated NLRP3 inflammasome contributed to the progression of late stage of melanoma (8), while significant downregulation of NLRP3 inflammasome was observed in human hepatocel- 
lular carcinoma (9). Currently, it remains unclear whether NLRP3 inflammasome has a beneficial or detrimental effect on the development of lung cancer. As the most frequent cause of major cancer incidence and mortality worldwide, lung cancer are included in two main histological categories: small cell lung cancer (SCLC) and non-small cell lung cancer (NSCLC). NSCLC comprises approximately $80 \%$ of all diagnosed lung cancer, and lung adenocarcinoma is the most common subtype of NSCLC. Thus, among lung cancer variants, adenocarcinoma is the most common histological subtype (1). Therefore, using human lung adenocarcinoma A549 cells, we investigated the role of NLRP3 inflammasome in the proliferation and migration of lung cancer cells and the potential underlying mechanisms.

\section{Materials and methods}

Reagents and cell culture. The A549 human alveolar epithelial adenocarcinoma cell line was purchased from the Institute of Biochemistry and Cell Biology of the Chinese Academy of Sciences (Shanghai, China). Cells were cultured in RPMI-1640 medium supplemented with $10 \%$ fetal bovine serum (FBS) (ScienCell, CA, USA) at $37^{\circ} \mathrm{C}$ in a humidified atmosphere of $5 \% \mathrm{CO}_{2}$. LPS and ATP were purchased from Sigma-Aldrich (St. Louis, MO, USA). The caspase-1 inhibitor benzyloxycarbonyl-tyrosine-valine-alanine-aspartate-fluoromethyl ketone (Z-YVAD-FMK) was purchased from PromoCell (Heidelberg, Germany). IL-18 binding protein (IL-18BP) was purchased from GenScript (Nanjing, China), and IL-1 receptor antagonist (IL-1Ra) was obtained from Fitzgerald Industries (MA, USA). Cells were stimulated by $1 \mu \mathrm{g} / \mathrm{ml}$ LPS for $8 \mathrm{~h}$ with or without $5 \mathrm{mmol} / \mathrm{l}$ ATP for the last half an hour. To inhibit the activation of caspase- 1 or block the IL-18 and IL-1 $\beta$ signal transduction, cells were pre-treated with $10 \mu \mathrm{mol} / 1 \mathrm{Z}-Y$ VAD-FMK (10), $1 \mu \mathrm{g} / \mathrm{ml}$ IL-18BP (11), and $2 \mu \mathrm{g} / \mathrm{ml}$ IL-1Ra (12) for half an hour prior to LPS stimulation, respectively.

Immunofluorescence assay. Cells were fixed with $4 \%$ paraformaldehyde for $30 \mathrm{~min}$, permeabilized with $0.5 \%$ Triton X-100 for $15 \mathrm{~min}$, and incubated with $5 \%$ bovine serum albumin (BSA) in phosphate-buffered saline (PBS) for $1 \mathrm{~h}$ at room temperature (RT). Subsequently, cells were incubated with primary antibodies against NLRP3 (1:200, Abcam, London, UK) and ASC (1:200, Cell Signaling Technologies, MA, USA) overnight at $4^{\circ} \mathrm{C}$. After three washes with PBS (5 min per wash), cells were incubated with Alexa Fluor 488-conjugated donkey anti-goat (1:1,000, Invitrogen, CA, USA) and Alexa Fluor 555-conjugated donkey anti-rabbit (1:500, Invitrogen) for $1 \mathrm{~h}$ at RT. After three washes with PBS, nuclei were stained with Hoechst 33342 (Beyotime, Nantong, China) for $30 \mathrm{~min}$. Immunofluorescence images were captured using a Zeiss LSM5 Live confocal laser scanning microscope (Carl Zeiss, Jena, Germany).

Enzyme-linked immunosorbent assay (ELISA). Cells were seeded in 24-well plates overnight. For NLRP3 inflammasome activation, cells were stimulated by $1 \mu \mathrm{g} / \mathrm{ml}$ LPS for $8 \mathrm{~h}$ with or without $5 \mathrm{mmol} / \mathrm{l}$ ATP for the last half an hour. After that, cell supernatants were collected, and centrifuged at $300 \mathrm{~g}$ for $8 \mathrm{~min}$ at $4^{\circ} \mathrm{C}$ for elimination of cells detached due to cell death, to generate cell-free medium preparations. Then supernatants were concentrated by centrifugation at $12,000 \mathrm{~g}$ for $30 \mathrm{~min}$ at $4^{\circ} \mathrm{C}$ through a column with a cut-off of $10 \mathrm{kDa}$ (Microcon; Merck-Millipore, Darmstadt, Germany). The levels of IL-1 $\beta$ and IL-18 in cell culture supernatants were measured by human ELISA kits from R\&D Systems (Minneapolis, MN, USA) and MBL (Nagoya, Japan), according to the manufacturer's instructions.

Cell proliferation assay. 5-ethynyl-2'-deoxyuridine (EdU) incorporation proliferation assay was performed to investigate the proliferation of A549 cells using a Cell-Light ${ }^{\mathrm{TM}}$ EdU Imaging detecting kit (RiboBio, Guangzhou, China). Cells were seeded in 6-well plates, and incubated for $24 \mathrm{~h}$ after different treatments. All of the EdU incorporation experiments were performed according to the manufacturer's protocol (13). The ratio of EdU-positive nuclei to total nuclei was calculated as the proliferation rate of cells in six random high-power fields per well. The cells were visualized by fluorescence microscopy (DM2500, Leica, Wetzlar, Germany).

Apoptosis detection. Cells were harvested after different treatments and washed with PBS. Then cells were resuspended in $500 \mu \mathrm{l}$ buffer, and stained with $5 \mu \mathrm{l}$ Annexin V FITC and $5 \mu \mathrm{lPI}$ (BD Biosciences, NJ, USA) for $15 \mathrm{~min}$ in the dark. The stained cells were detected by flow cytometry (BD Biosciences).

Cell migration assays. Cell migration was examined using scratch assay and Transwell chamber migration assay. For scratch assay, cells were seeded in 6-well plates. Until the cells reached $100 \%$ confluence forming a monolayer, a sterile $50-\mu 1$ pipette tip was used to create a scratch on cell monolayer after different treatments. The wounds were photographed at baseline and $24 \mathrm{~h}$ later, using a phase contrast microscope (Nikon, Tokyo, Japan). For Transwell chamber migration assay, $5 \times 10^{4}$ cells were resuspended in $200 \mu \mathrm{l}$ of serum-free medium in the upper chamber, and $600 \mu \mathrm{l}$ medium with different treatments was placed in the bottom chamber. Then, $10 \%$ FBS was added to the lower chamber to act as a chemoattractant. The Transwell system (24-well, $8 \mu \mathrm{m}$, Corning, NY, USA) was incubated for $4 \mathrm{~h}$ at $37^{\circ} \mathrm{C}$ and $5 \% \mathrm{CO}_{2}$. Non-migrated cells on the top of the membrane were gently removed with a cotton swab. The cells that migrated through the pores onto the lower side of the membrane were fixed with $4 \%$ paraformaldehyde for $30 \mathrm{~min}$. Finally, the cells were stained with crystal violet (Beyotime) and counted using a phase contrast microscope (Nikon).

Downregulation of NLRP3 expression by short hairpin RNA (shRNA) interference. To knock down the NLRP3 expression, the A549 cells were transfected with lentiviral-mediated shRNA. The cells were transfected by lentiviral particles at a multiplicity of infection of 20-30 with control shRNA (shCtrl) or NLRP3 shRNAs (shNLRP3) (GenePharma, Shanghai, China), according to the manufacturer's instructions. Downregulation of NLRP3 expression was verified by reverse transcriptase polymerase chain reaction (RT-PCR) and western blotting (data not shown).

RNA isolation and RT-PCR. Total RNA was extracted from cells using TRIzol (Invitrogen). Reverse transcription was 
A

ASC

NLRP3

Nuclei

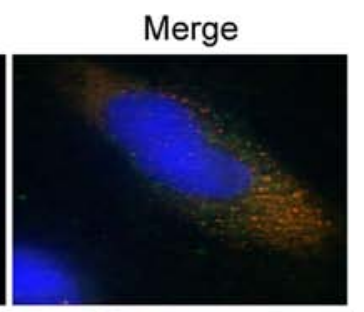

Control
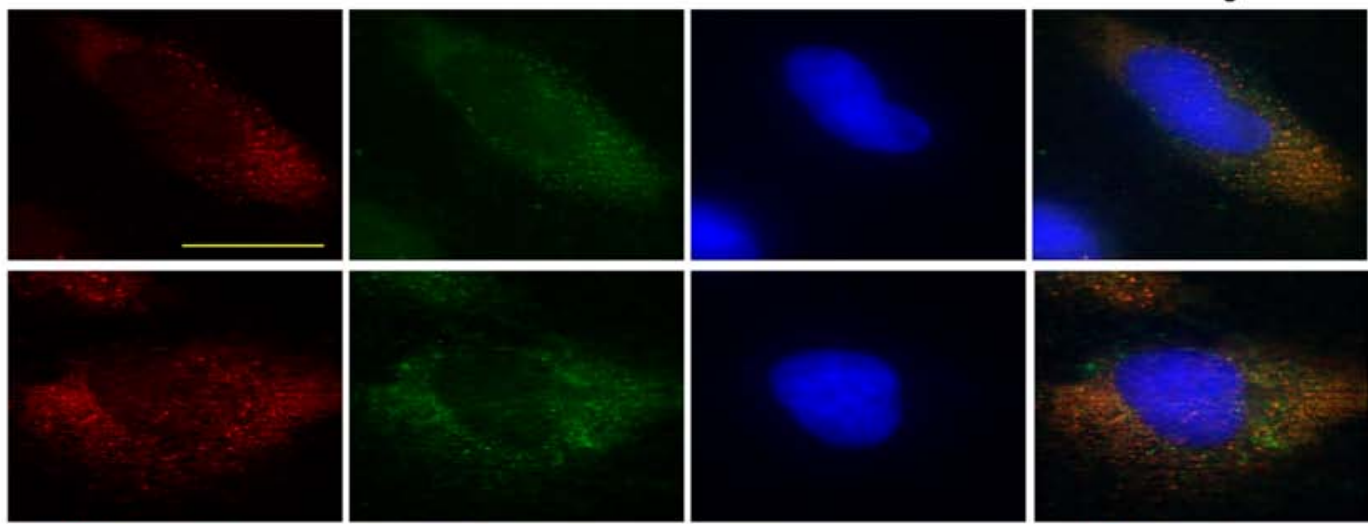

LPS
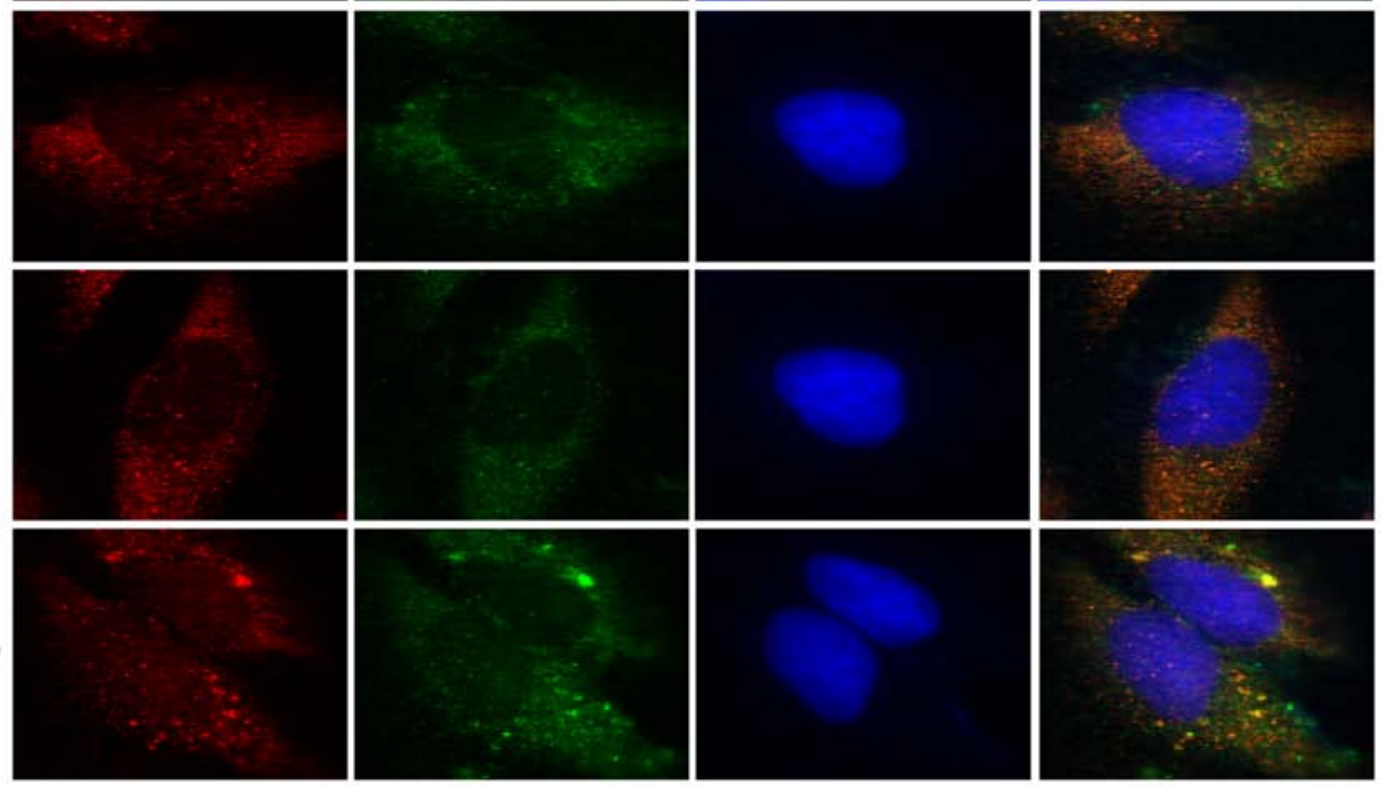

B
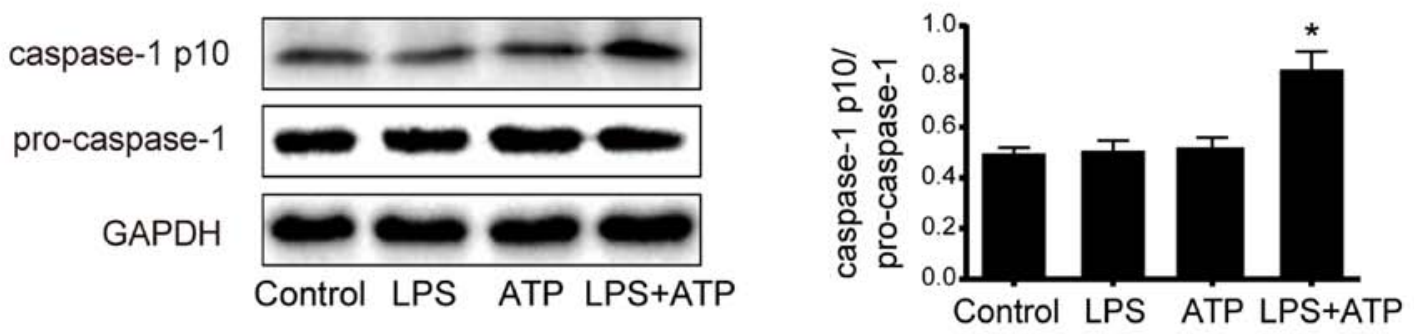

C
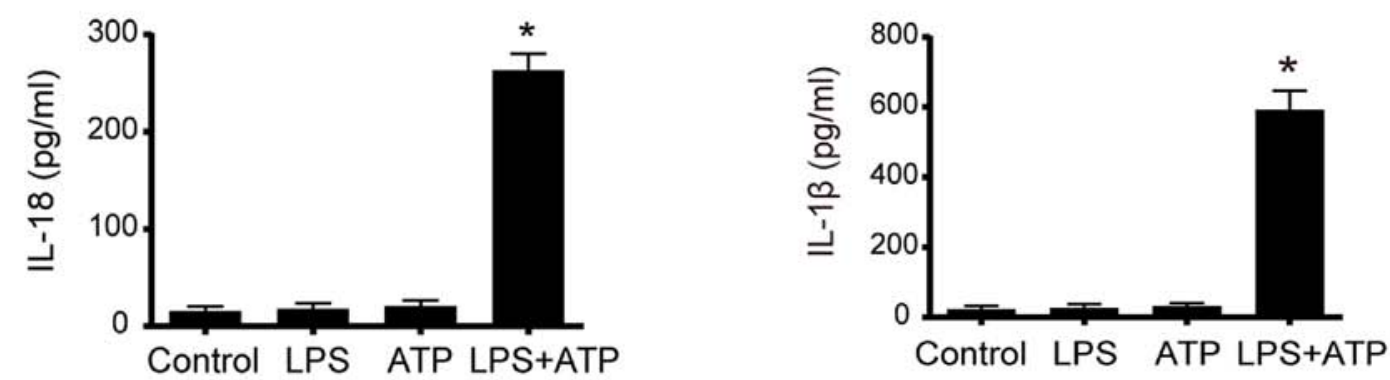

Figure 1. Effects of LPS and ATP on the activation of NLRP3 inflammasome in A549 cells. (A) Subcellular localization of inflammasome proteins was observed by immunofluorescence. Intracellular NLRP3 and ASC colocalized in LPS+ATP-treated cells but rarely in cells treated with LPS or ATP alone. The experiment was performed 3 times. (B) The expression of active caspase-1 p10 was significantly higher in LPS+ATP group than in control group. (C) The concentration of cleaved IL-18 and IL-1 $\beta$ in culture supernatants were significantly elevated in LPS+ATP group, not in LPS or ATP alone group. The values are presented as means \pm SEM of five replicates. Scale bar, $20 \mu \mathrm{m}$. $\mathrm{P}<0.05$ compared with the control group.

performed using a reverse transcription kit (Takara, Shiga, Japan) according to the manufacturer's instructions. Standard real-time quantitative PCR was performed using the following primers: NLRP3: forward 5'-AAGGGCCATGGACTATT TCC-3' and reverse 5'-GACTCCACCCGATGACAGTT-3'; GAPDH: forward 5'-GAAGGTGAAGGTCGGAGTC-3' and reverse 5'-GAAGATGGTGATGGGATTTC-3'. All primers were synthesized by Invitrogen Life Technologies. The mRNA levels were quantified by SYBR Green Technology. Fold changes in gene expression were calculated using the $2^{-\Delta \Delta \mathrm{CT}}$ method (14).

Western blot analysis. Cells were lysed on ice in lysis buffer with $1 \%$ EDTA and $1 \%$ protease inhibitor cocktail (Thermo 
Fisher Scientific, MA, USA). The total protein concentrations were quantified by BCA method (Beyotime). Proteins $(60-100 \mu \mathrm{g})$ were resolved by SDS-PAGE and transferred to PVDF membranes (Millipore, MA, USA). After blocking with $5 \%$ milk for $1 \mathrm{~h}$ at $\mathrm{RT}$, the membranes were incubated with primary antibodies against total and phosphorylated protein kinase B (Akt), extracellular regulated protein kinase $1 / 2$ (ERK1/2), cyclic adenosine monophosphate (cAMP) response element binding protein (CREB), NLRP3, E-cadherin, GAPDH (Cell Signaling Technologies), caspase-1 (Santa Cruz, CA, USA), and Snail (Abcam) at $4^{\circ} \mathrm{C}$ overnight. After three 10-min washes with Tris-buffered saline containing $0.1 \%$ Tween-20 (TBST), the blots were incubated with HRP-conjugated secondary antibodies (Bioworld, Nanjing, China), and signals were detected by enhanced chemiluminescent reagents and analyzed with Bio-Rad Gel Doc/Chemi Doc Imaging System and Quantity One software (Hercules, CA, USA).

Statistical analysis. All the data are expressed as the mean \pm SEM. Differences between means were analyzed using one-way analysis of variance (ANOVA) or two-way ANOVA followed by Student-Newman-Keuls tests for multiple comparisons. Statistical significance was defined as $\mathrm{P}<0.05$. All analyses were performed using the Statistical Package for Social Sciences statistical software (SPSS), version 20.0 (SPSS Inc., Chicago, IL, USA).

\section{Results}

LPS + ATP activates NLRP3 inflammasome in A549 cells. To investigate whether LPS and ATP trigger the formation of NLRP3 inflammasome in A549 cells, the association between NLRP 3 and ASC was determined by immunofluorescence. As shown in Fig. 1A, many intracellular NLRP3 and ASC colocalizations were found in punctate spot style after the stimulation of LPS+ATP. However, less NLRP3 and ASC colocalizations were detected in the control group and the LPS or ATP single-treated group. Consistently, western blot analysis showed that the expression of active caspase-1 p10 significantly increased by stimulation of LPS+ATP (Fig. 1B). Moreover, the extracellular levels of IL-18 and IL-1 $\beta$ significantly increased in the LPS+ATP group compared to the other groups (Fig. 1C). Together, these data demonstrate that LPS+ATP induced the assembly and activation of NLRP3 inflammasome in A549 cells.

Activation of NLRP3 inflammasome enhances A549 cell proliferation. EdU incorporation assay was used to determine the cell proliferation. As shown in Fig. 2A, a significant increase in EdU-positive cells was found after the treatment of LPS+ATP, but not LPS or ATP alone. NLRP3 inflammasome activation involves several stages, including NLRP3 inflammasome assembly, pro-IL-1 $\beta$ and pro-IL-18 enzymatic cleavage by active caspase-1, and subsequent effects following the release of mature IL-1 $\beta$ and IL-18. Therefore, inhibiting NLRP3 inflammasome by NLRP3 downregulation, caspase-1 inhibitor Z-YVAD-FMK, IL-18BP and IL-1Ra was used to further confirm the effects of NLRP3 inflammasome activation on A549 cells. The downregulation of NLRP3 by shRNA interference was confirmed by RT-PCR and western blotting.
The NLRP3 expression in shNLRP3 was downregulated to $18 \%$ of shCtrl (Fig. 2B). As shown in Fig. 2C, LPS+ATP increased the number of EdU-positive cells in the shCtrl cells, but not in the shNLRP3 cells. The caspase-1 inhibitor Z-YVAD-FMK had no effect on A549 proliferation under base condition, but it attenuated LPS+ATP-induced cell proliferation (Fig. 2D). Moreover, neutralization of IL-18 activity with IL-18BP or inhibition of IL-1 $\beta$ activity with IL-1Ra attenuated the LPS+ATP-induced enhancement of proliferation, while the combined use of IL-18BP and IL-1Ra abolished the pro-proliferative effect of LPS+ATP (Fig. 2E). As shown in Fig. 2F, flow cytometry analysis of Annexin V-FITC/PI-staining revealed that LPS, ATP, and LPS+ATP did not alter apoptosis of A549 cells.

Activation of NLRP3 inflammasome enhances A549 cell migration. Cell migration was investigated by using scratch assay and Transwell chamber migration assay. As shown in Fig. 3A, scratch assay demonstrated that LPS+ATP elicited a significant increase in the migrated distance compared with the control group. The results of Transwell chamber migration assay were consistent with the scratch assay (Fig. 3B). In shCtrl A549 cells, LPS+ATP also enhanced cell migration in scratch assay and Transwell chamber migration assay. However, the LPS+ATP-induced enhancement of cell migration was abolished by NLRP3 knockdown (Fig. 3C and D). In addition, caspase-1 inhibitor Z-YVAD-FMK attenuated LPS+ATP-induced migration in both scratch assay and Transwell chamber migration assay (Fig. 3E and F). IL-18BP or IL-1Ra also attenuated LPS+ATP-induced migration, while the combined treatment of IL-18BP and IL-1Ra reversed the LPS+ATP-induced enhancement of cell migration (Fig. 3G and $\mathrm{H})$.

Activation of NLRP3 inflammasome enhances the phosphorylation of Akt, ERK1/2, and CREB. To investigate the potential molecular mechanisms of activated NLRP3 inflammasome on A549 cell proliferation, the phosphorylation of two intracellular kinases (Akt and ERK1/2) and a transcription factor (CREB) involved in cell proliferation was determined by western blotting. As shown in Fig. 4, activation of NLRP3 inflammasome by LPS+ATP increased the phosphorylation of Akt,ERK1/2, and CREB. However, downregulation of NLRP3 reversed the phosphorylation of Akt, ERK1/2, and CREB induced by the treatment of LPS+ATP (Fig. 4A). Caspase-1 inhibitor Z-YVAD-FMK abolished LPS+ATP-induced Akt phosphorylation, and attenuated LPS+ATP-induced ERK1/2 and CREB phosphorylation (Fig. 4B). IL-18BP abolished LPS+ATP-induced Akt phosphorylation, and attenuated ERK1/2 and CREB phosphorylation, while IL-1Ra abolished ERK1/2 phosphorylation, and attenuated Akt and CREB phosphorylation. Moreover, the combination of IL-18BP and IL-1Ra reversed the phosphorylation of Akt, ERK1/2 and CREB induced by the activation of NLRP3 inflammasome (Fig. 4C).

Activation of NLRP3 inflammasome downregulates E-cadherin expression and upregulates Snail expression. The cellular adhesion molecule E-cadherin and the transcription factor Snail are two important factors involved in inflamma- 


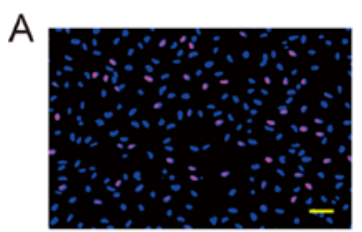

Control

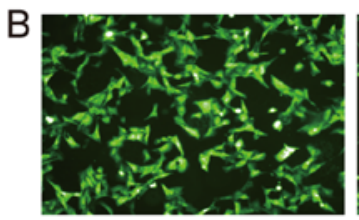

shCtrl

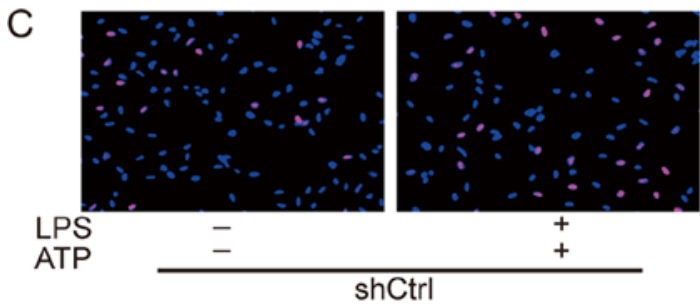

D

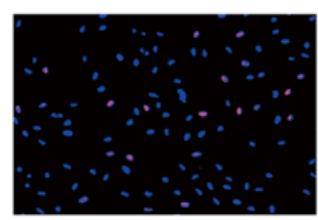

LPS

ATP

Z-YVAD-FMK -

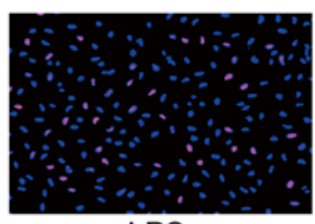

LPS

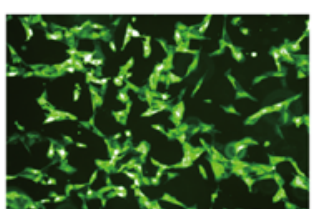

shNLRP3

$+$

$+$

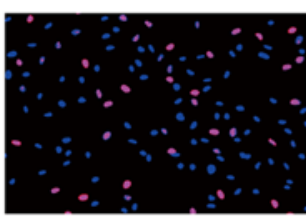

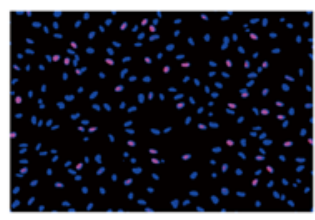

ATP
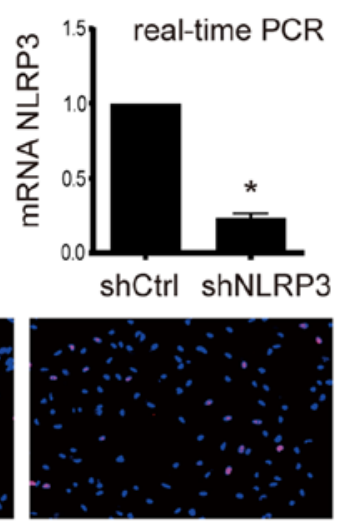

-

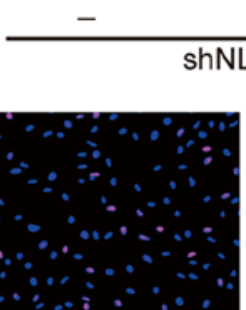

$+$

$+$

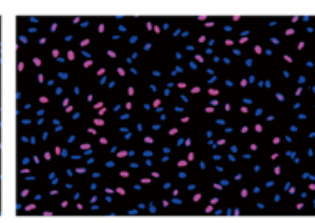

LPS+ATP

Western blot

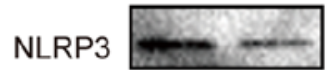

GAPDH

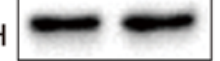

shCtrl shNLRP3
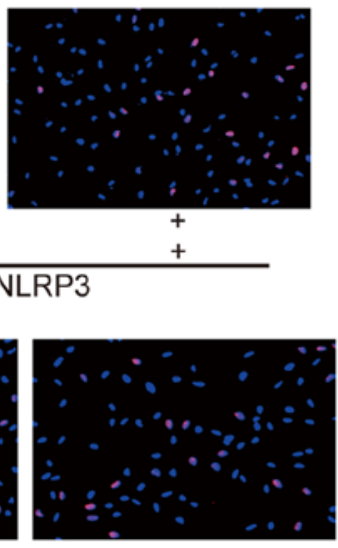

$-$

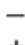

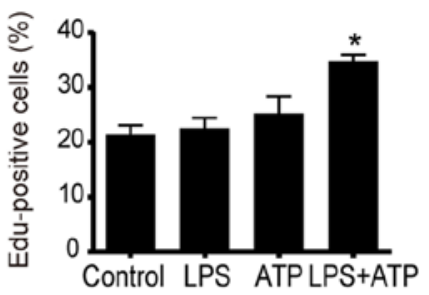

Control LPS ATPLPS+ATP
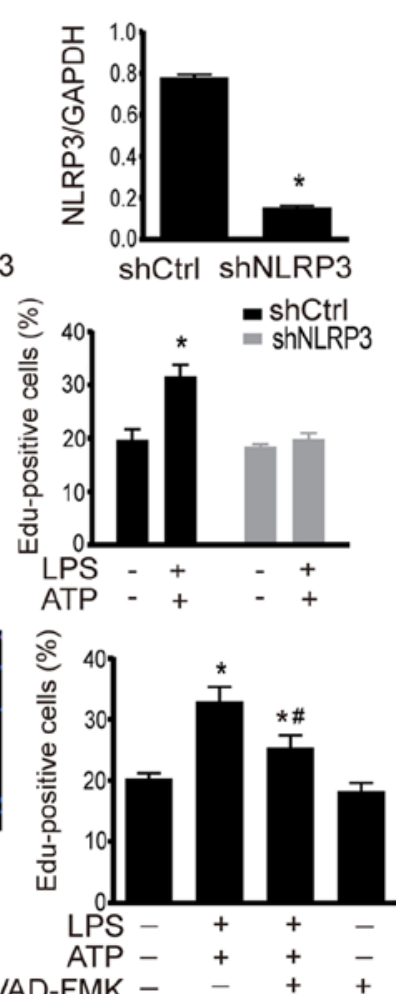

Z-YVAD-FMK - -++

E
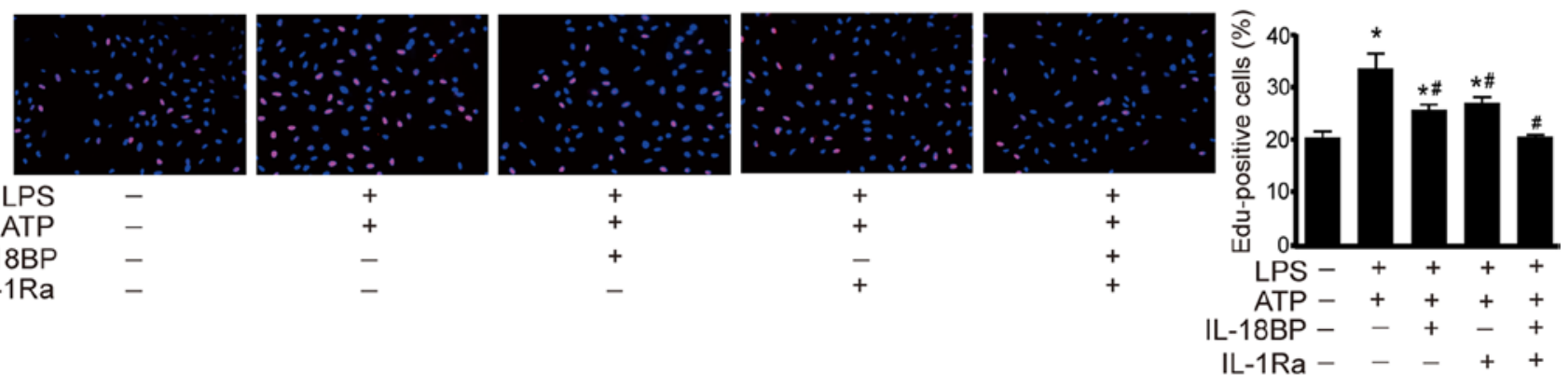

F
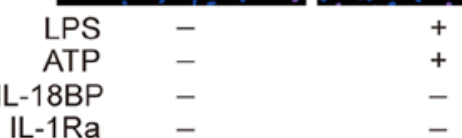

$-$
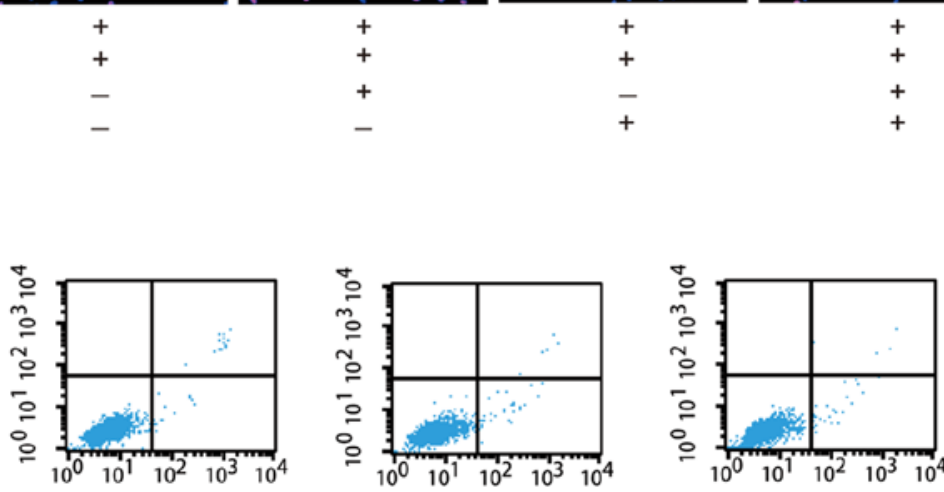

Annexin

ATP

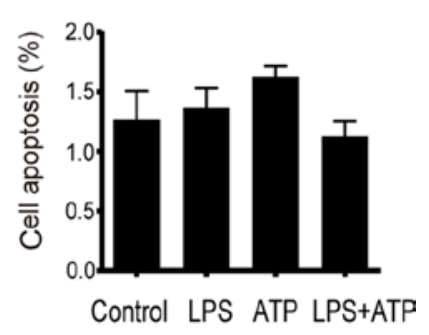

Figure 2. Effects of NLRP3 inflammasome activation on LPS+ATP-induced proliferation. (A) Activated NLRP3 inflammasome by LPS+ATP enhanced cell proliferation. (B) NLRP3 protein expression was downregulated by shNLRP3 interference to $18 \%$ of that in shCtrl. (C) NLRP3 downregulation abolished LPS+ATP-induced cell proliferation. (D) Caspase-1 inhibitor Z-YVAD-FMK attenuated LPS+ATP-induced proliferation. (E) IL-18BP, or IL-1Ra also inhibited LPS+ATP-induced proliferation, and combined use of IL-18BP and IL-1Ra abolished LPS+ATP-induced proliferation. (F) LPS, ATP, and LPS+ATP had no effect on the apoptosis of A549 cells. Scale bar, $50 \mu \mathrm{m}$. These experiments were performed 4 times. ${ }^{*} \mathrm{P}<0.05$ compared with the control group; ${ }^{\sharp} \mathrm{P}<0.05$ compared with the LPS+ATP group.

tion-induced cancer cell migration (15). As shown in Fig. 5A and 5B, LPS+ATP treatment resulted in E-cadherin down- regulation and Snail upregulation in A549 cells, while these effects were abolished by NLRP3 interference or caspase-1 

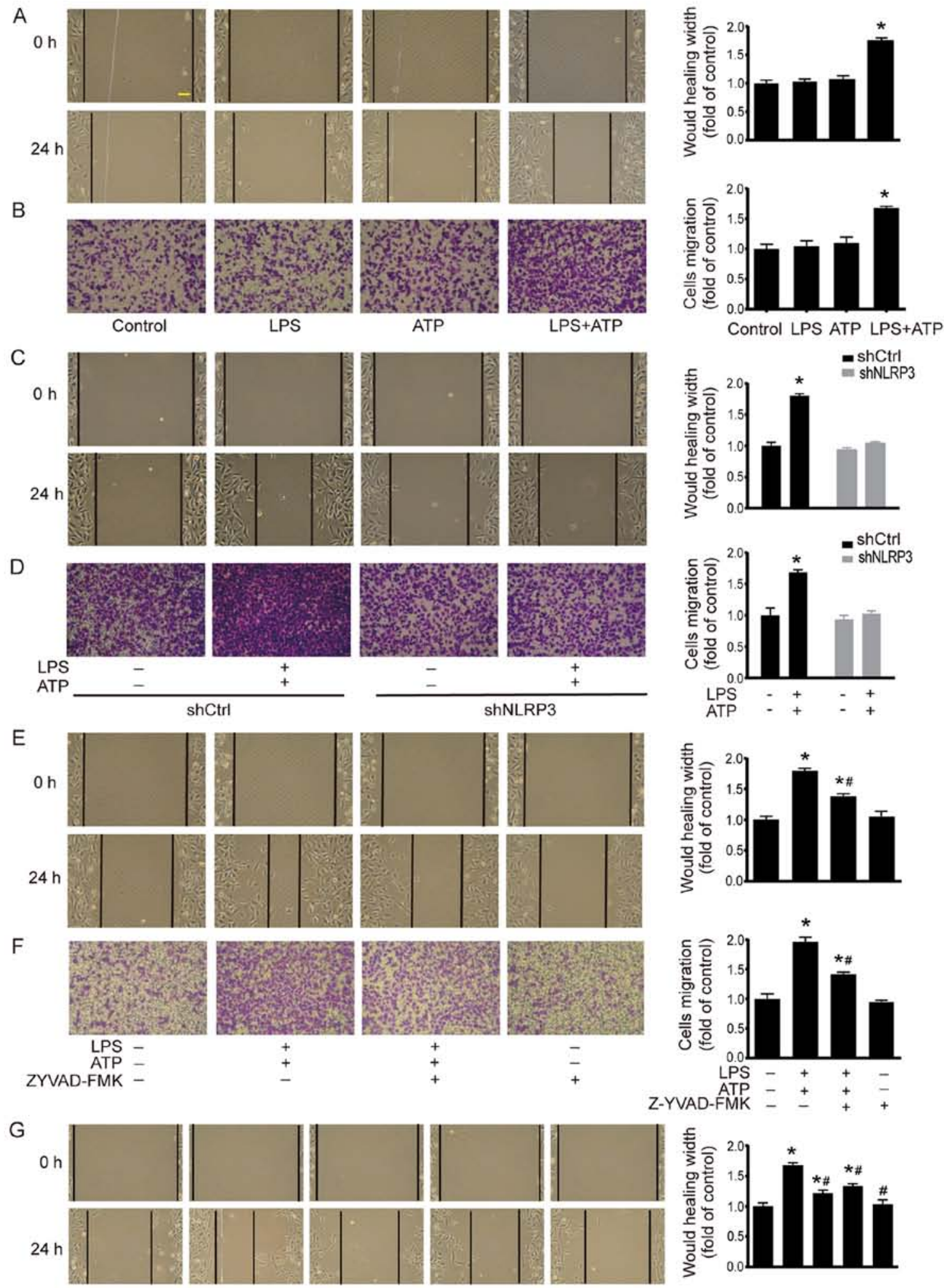

$\mathrm{H}$
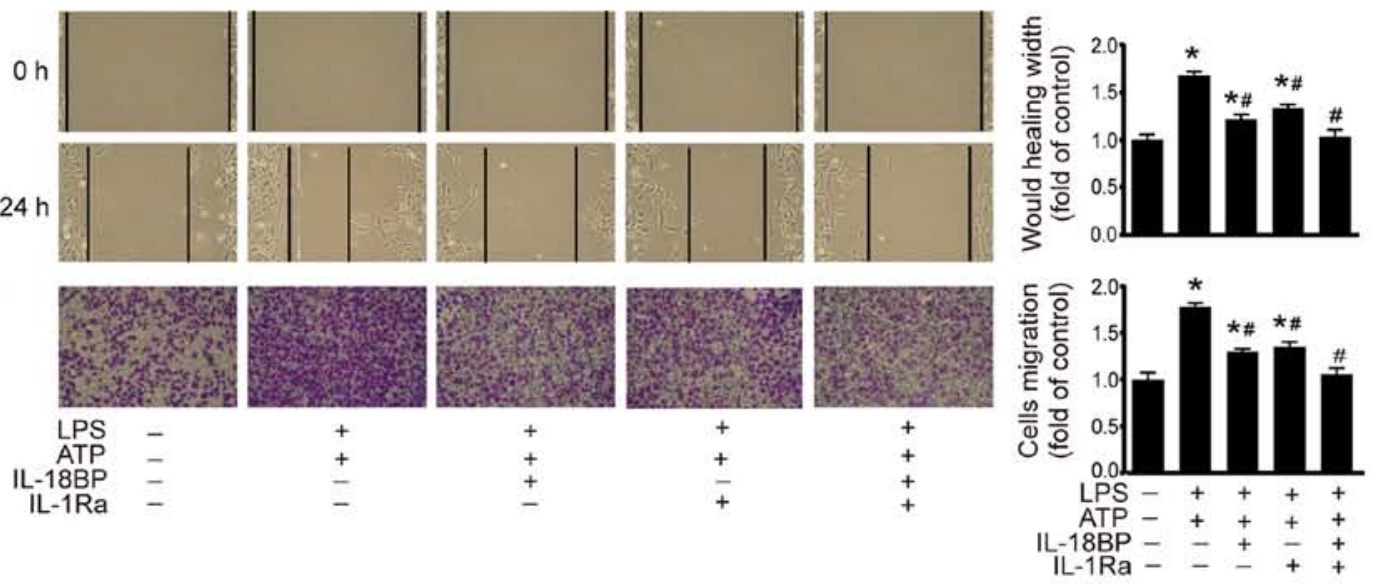

Figure 3. Effects of NLRP3 inflammasome activation on LPS+ATP-induced migration. (A) Scratch assay and (B) Transwell chamber migration assay showed that LPS+ATP-induced NLRP3 inflammasome activation enhanced A549 cell migration. (C and D) NLRP3 downregulation abolished LPS+ATP-induced cell migration. (E and F) Caspase-1 inhibitor Z-YVAD-FMK suppressed LPS+ATP-induced cell migration. (G and H) IL-18BP or IL-1Ra inhibited LPS+ATPinduced cell migration, and the combined use of IL-18BP and IL-1Ra reversed LPS+ATP-induced cell migration. Scale bar, $100 \mu \mathrm{m}$. The data are reported as means \pm SEM for four independent experiments. "P<0.05 compared with the control group; ${ }^{*} \mathrm{P}<0.05$ compared with the LPS $+\mathrm{ATP}$ group. 
A

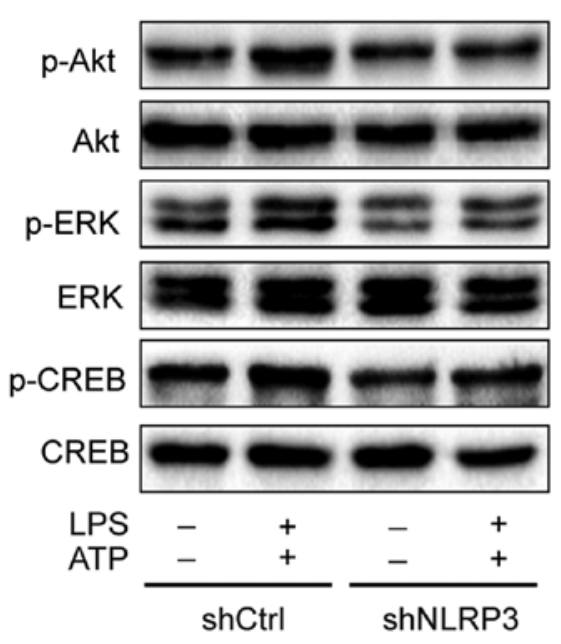

B
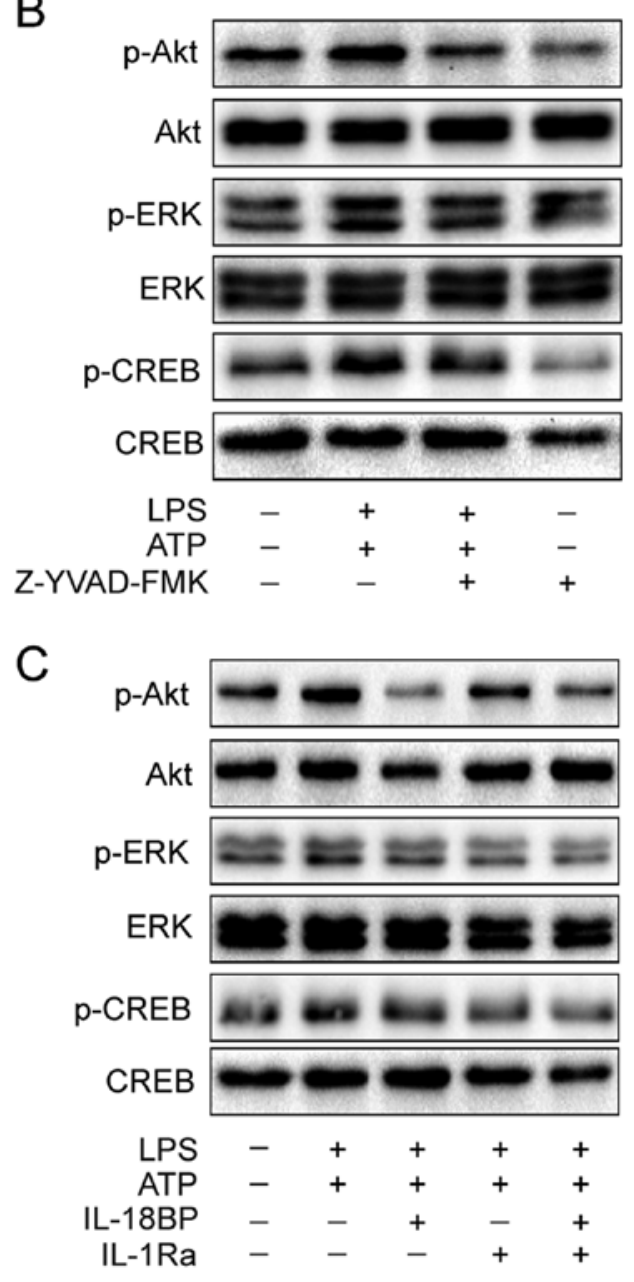
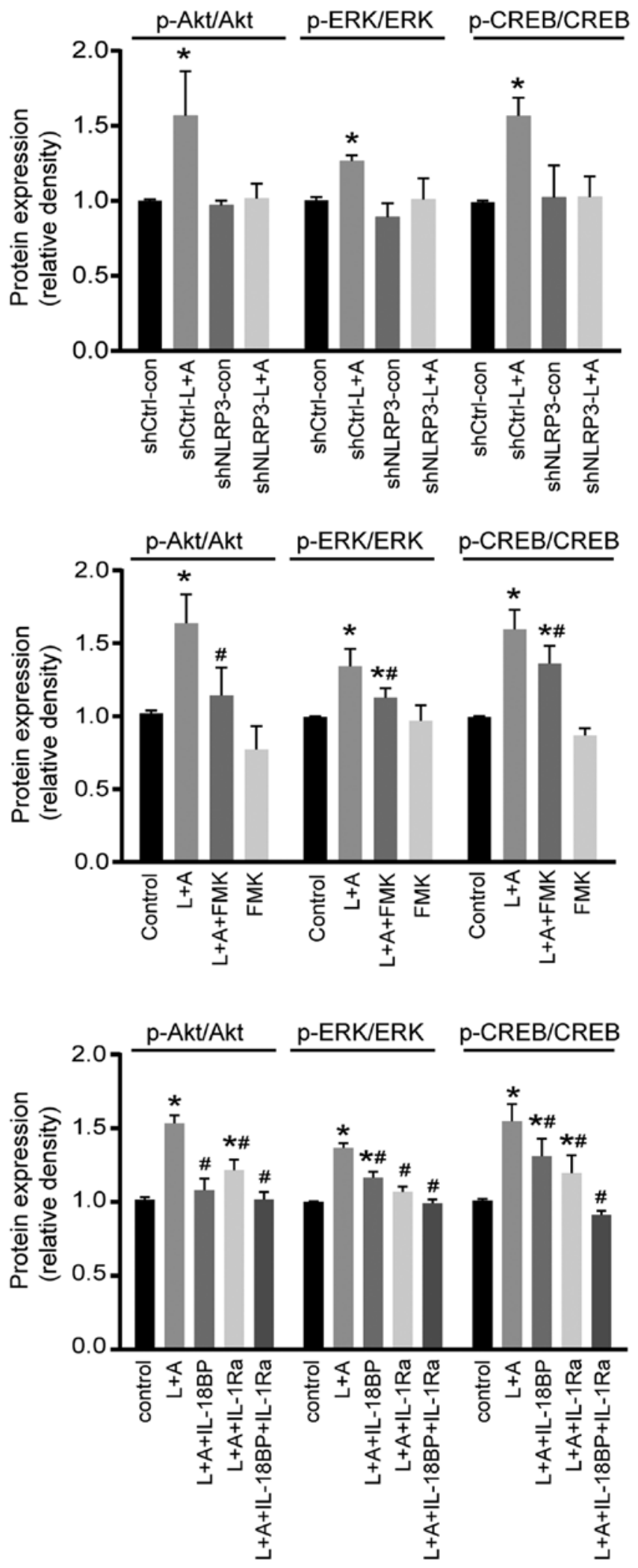

Figure 4. Effects of NLRP3 inflammasome activation on Akt, ERK1/2, and CREB phosphorylation. (A) Downregulation of NLRP3 reversed the LPS+ATPinduced phosphorylation of Akt, ERK1/2 and CREB. (B) Caspase-1 inhibitor Z-YVAD-FMK abolished LPS+ATP-induced Akt phosphorylation and inhibited ERK1/2 and CREB phosphorylation. (C) L-18BP, or IL-1Ra inhibited LPS+ATP-induced phosphorylation of Akt, ERK1/2 and CREB, and combined use of IL-18BP and IL-1Ra abolished the LPS+ATP-induced phosphorylation of Akt, ERK1/2 and CREB. L, LPS; A, ATP; FMK, Z-YVAD-FMK. Four independent experiments were examined. "P $<0.05$ compared with the control group; ${ }^{*} \mathrm{P}<0.05$ compared with the LPS+ATP group.

inhibitor. Moreover, LPS+ATP-induced E-cadherin downregulation and Snail upregulation were inhibited by IL-18BP or IL-1Ra, and reversed by the combined use of IL-18BP and IL-1Ra (Fig. 5C). 
A

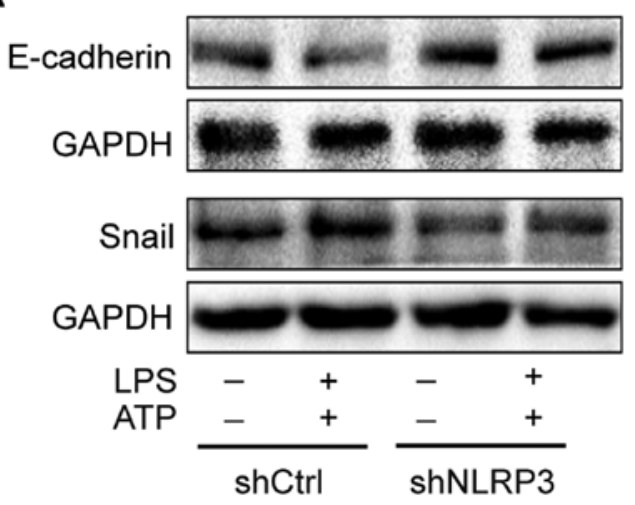

B

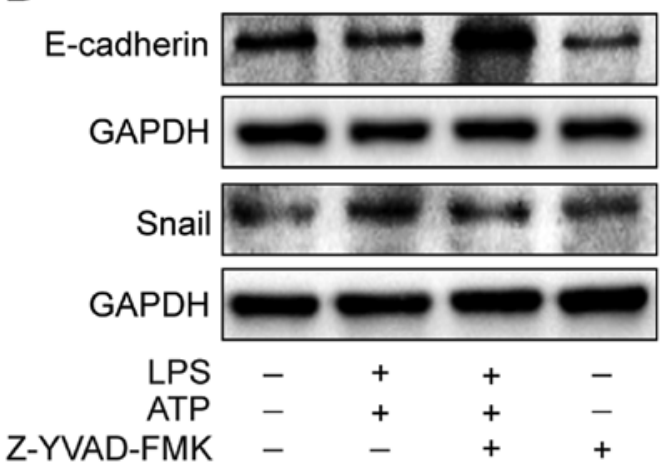

C

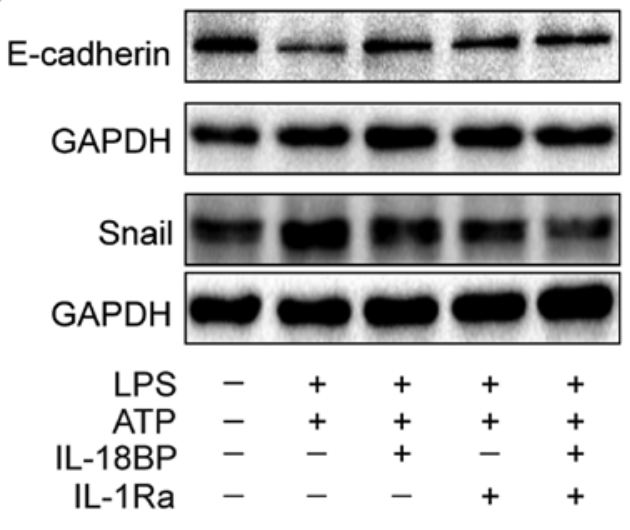

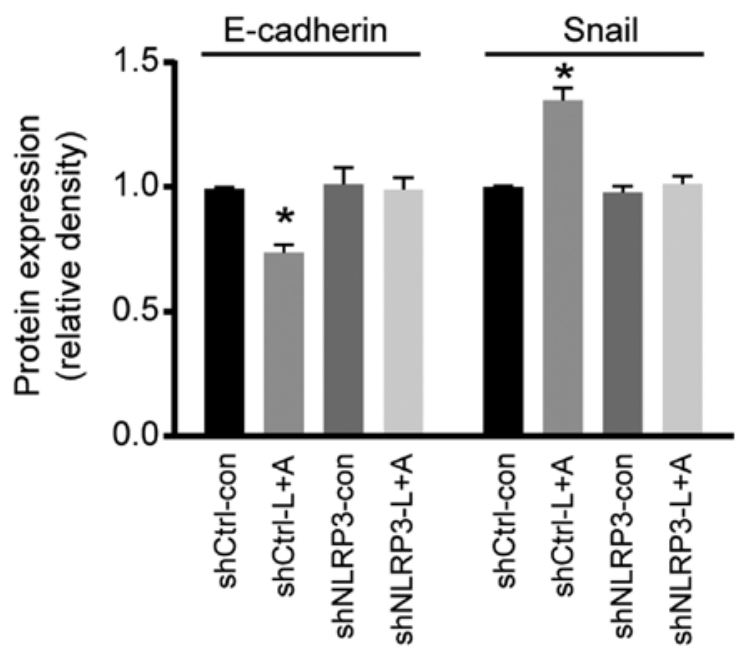
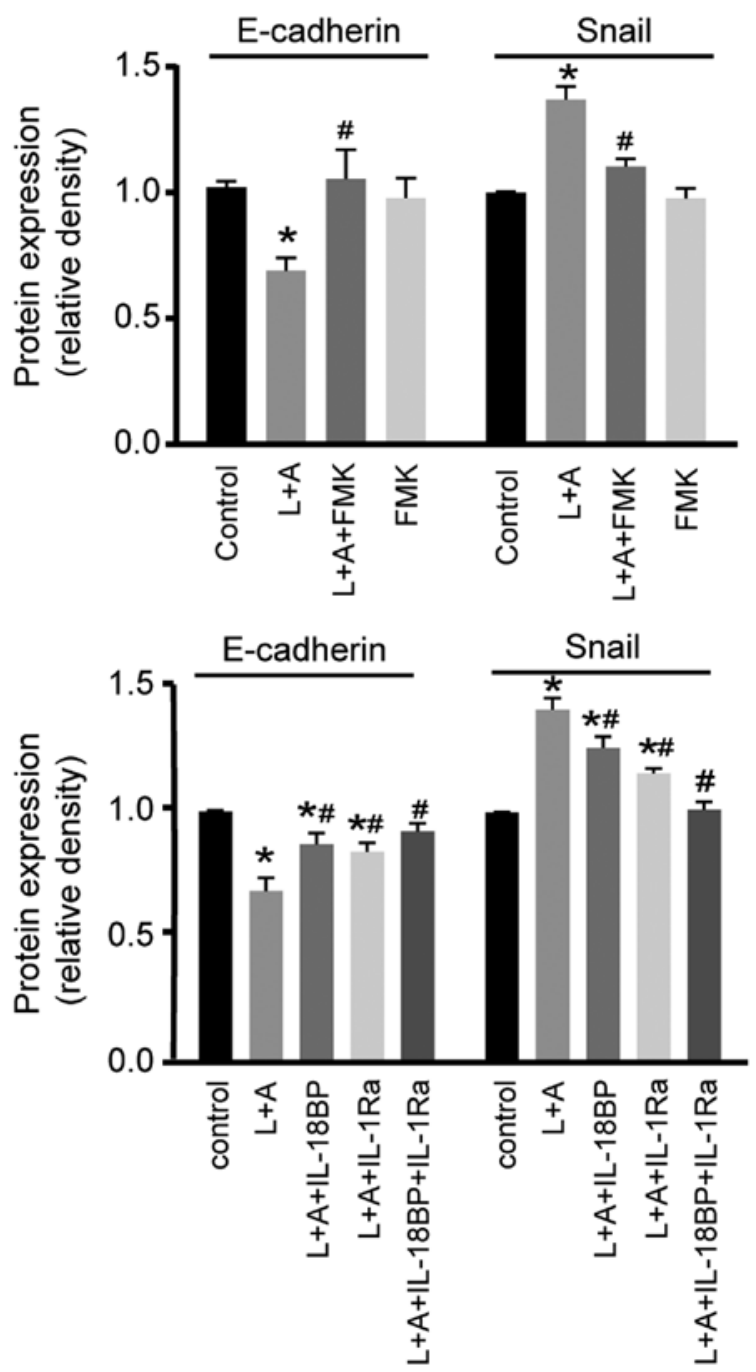

Figure 5. Effects of NLRP3 inflammasome activation on the expression of Snail and E-cadherin. (A) Downregulation of NLRP3 reversed the LPS+ATPinduced downregulation of E-cadherin and upregulation of Snail. (B) Caspase-1 inhibitor Z-YVAD-FMK abolished LPS+ATP-induced downregulation of E-cadherin and upregulation of Snail. (C) L-18BP, or IL-1Ra inhibited LPS+ATP-induced downregulation of E-cadherin and upregulation of Snail, while the combined use of IL-18BP and IL-1Ra abolished LPS+ATP-induced downregulation of E-cadherin and upregulation of Snail. L, LPS; A, ATP; FMK, Z-YVAD-FMK. Four independent experiments were examined. "P<0.05 compared with the control group; ${ }^{*} \mathrm{P}<0.05$ compared with the LPS+ATP group.

\section{Discussion}

Cancer-related inflammation supplies cytokines, chemokines, and extracellular matrix, to promote tumor growth and metas- tasis. Currently, inflammasomes, which sense exogenous and endogenous dangers and initiate inflammatory responses, are considered to contribute the development of cancer-related inflammation and have complex functions in carcinogenesis 


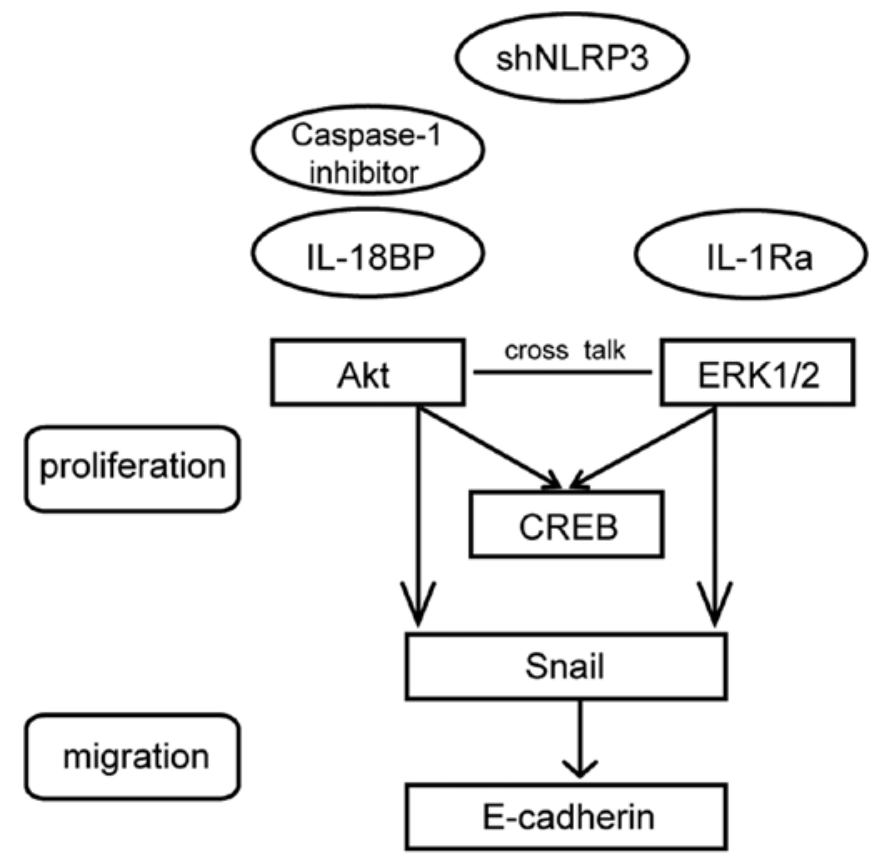

Figure 6. A schematic model to illustrate the mechanisms. Caspase-1 inhibitor Z-YVAD-FMK suppressed the LPS+ATP-induced phosphorylation of Akt more effectively than that of ERK1/2. IL-18BP functioned more effectively on the phosphorylation of Akt while IL-1Ra functioned more effectively on the phosphorylation of ERK1/2. Snail, which represses E-cadherin transcription, and can be mediated by Akt and ERK1/2.

(16). Among the inflammasomes, NLRP3 is widely expressed in a number of cells including epithelial cells, macrophages, dendritic cells and keratinocytes. NLRP3 inflammasome can be activated by a number of stimuli (17). It has been well documented that NLRP3 inflammasome plays important roles in inflammatory disease, autoimmune disease, and in particular, several types of cancer (18). However, the roles of NLRP3 inflammasome in different cancers are cell- and tissue-specific $(8,19)$. Thus, in-depth understanding the effects of NLRP3 inflammasome in lung cancer cells and the underlying mechanisms may offer new insights into tumor therapy. In the present study, we demonstrated that NLRP3 inflammasome activation exacerbated the proliferation and migration of A549 cells. These effects were attenuated by inhibiting the activity of NLRP3 inflammasome by different ways such as downregulating NLRP3 expression, inhibiting the activity of caspase-1, or blocking IL-18 and/or IL-1 $\beta$ signal transduction. Thus, NLRP3 inflammasome could be an important molecule mediating the proliferation and migration of A549 cells.

Activation of NLRP3 inflammasome commonly includes priming with a TLR agonist (such as LPS) and activating with a second stimulus (such as ATP) (20). Once activated, NLRP3 inflammasome triggers proteolytic processing of pro-caspase-1 into its active form, caspase-1 (p10 or p20), which subsequently cleaves pro-IL-1 $\beta$ and pro-IL-18 to mature bioactive forms. Our results showed that the downregulation of NLRP3 abolished the effects of LPS+ATP on the proliferation and migration of A549 cells. However, inhibiting the activity of caspase-1, which is downstream of NLRP3, only partially attenuated the effects of LPS+ATP.
Furthermore, the combined use of IL-1Ra and IL-18BP to block the IL-1 $\beta$ and IL-18 signaling pathways, which are downstream of caspase-1, reversed the effects of LPS+ATP. These results suggest that: i) NLRP3 inflammasome activation-induced IL-1 $\beta$ and IL-18 may work through mechanisms other than the caspase-1 pathway; ii) the effects of activated NLRP3 inflammasome on A549 cell proliferation and migration should be mediated by releasing IL-1 $\beta$ and IL-18 in an autocrine or paracrine manner. Although caspase- 1 activation is the major downstream event of NLRP3 inflammasome assembly, recent studies report that NLRP3 inflammasome can also activate caspase- 8 (21). In addition, caspase- 8 is also involved in the maturation of IL-1 $\beta$ and IL-18 by inducing a non-canonical process of releasing IL-1 $\beta$ (22-24) and IL-18 (25). In this regard, we consider that NLRP3 inflammasome can mediate the release of IL-1 $\beta$ and IL-18 through a caspase1-dependent or -independent pathway.

In the present study, blockage of IL-18 or IL-1 $\beta$ signaling alleviated the effects of activated NLRP3 inflammasome on A549 cell proliferation and migration. This result indicates that both IL-18 and IL- $1 \beta$ could contribute to the progression of lung adenocarcinoma. In a mouse model, Lewis lung carcinoma cells engineered to produce IL-1 $\beta$ exhibited increased tumor growth and expression of angiogenic factors (26). In non-small cell lung cancer (NSCLC) patients, serum IL-1 $\beta$ is significantly elevated compared with healthy donors (27). Moreover, in vitro studies show that IL-1 $\beta$ promotes the proliferation and migration of NSCLC cells by repressing the expression of microRNA-101 through the COX2-HIF1 $\alpha$ pathway (27). In other cancers, it has been reported that IL-1 $\beta$-mediated inflammation contributes to the development and progression of melanoma (8). IL-18 also belongs to the IL-1 superfamily. The biologic activity of IL-18 is mainly regulated by enzymatic processing, whereas IL-1 $\beta$ is controlled at the transcriptional level (28). Although there are some differences between IL-18 and IL-1 $\beta$, IL-18 also has a tumor-promoting activity similar to that of IL-1 $\beta$. In lung cancer patients, IL-18 level in induced sputum is significantly higher than that in healthy controls (29). Moreover, in gastric cancer, IL-18 increases tumor cell proliferation (30), promotes cell migration (31), and enhances angiogenesis (32). IL-18 regulates hepatic melanoma metastasis, favoring the adhesion of melanoma cells to liver (33). These effects of IL-1 $\beta$ and IL-18 on the proliferation and migration of A549 cells were also confirmed in our study. Moreover, the combined use of IL-1 Ra and IL-18BP reversed the effects of activated NLRP3 inflammasome. Therefore, we assume that NLRP3 inflammasome activation can regulate the proliferation and migration of A549 cells by releasing IL-1 superfamily cytokines in an autocrine or paracrine manner (34).

Uncontrolled tumor cell growth and metastasis mainly result from the disruptions of regulatory signaling pathways. The Akt and ERK1/2 are two important signaling molecules in tumor proliferation. Our data demonstrated that activation of NLRP3 inflammasome could enhance the phosphorylation of Akt, ERK1/2 and CREB. The Akt pathway plays a pivotal role in fundamental cellular functions by phosphorylating a variety of substrates. Another important signal transduction pathway involves ERK1/2, which forms major cell-proliferation signaling pathways from the cell surface to the nucleus. 
Recent studies have demonstrated crosstalk between Akt and ERK1/2 signaling $(35,36)$. It is well documented that Akt and ERK1/2 kinase can activate CREB, which is a key transcription factor for cell proliferation (37). In the present study, caspase-1 inhibitor Z-YVAD-FMK suppressed the LPS+ATPinduced phosphorylation of Akt more effectively than that of ERK1/2. Moreover, IL-18BP functioned more effectively on the phosphorylation of Akt while IL-1Ra functioned more effectively on the phosphorylation of ERK1/2. Previous studies have indicated that IL-18 promotes proliferation via Akt pathway $(38,39)$ in various cell types, but has few effects on ERK1/2 activation (40). ERK1/2 pathway participates in IL-1 $\beta$-induced sensitization of nociception in rats (41). However, it is also demonstrated that Akt and ERK1/2, which are simultaneously involved in IL-18 or IL- $1 \beta$ signaling, act equally $(42,43)$. Therefore, both Akt and ERK1/2 signaling are involved in activated NLRP3 inflammasome-induced A549 cell proliferation. We provide a schematic model (Fig. 6) to illustrate clearly the mechanisms. However, the precise signal transduction pathways need to be further investigated by using kinase inhibitors.

Tumor metastasis is one of the most common events that lead to mortality of cancer. There are several molecules involved in tumor metastasis, such as E-cadherin (44), matrix metalloproteinases (MMPs) $(45,46)$ and chemokine (C-X-C motif) ligand (CXCL) (47). E-cadherin, which is a prime adhesion molecule on cell membrane of epithelial cells and epithelia-derived cancer cells, participates in the architectural maintenance of epithelial tissues (48). Snail is a zinc-finger transcription factor which represses E-cadherin transcription (49). Our results showed that NLRP3 inflammasome activation could downregulate the expression of E-cadherin and upregulate the expression of Snail. In human NSCLC patients, reduced E-cadherin expression correlates with lymph nodes metastasis (50) and reduced overall survival (44). Upregulation of Snail is associated with poor prognosis and promotes the progression of NSCLC in vivo (51). Downregulation of Snail expression not only inhibits $\mathrm{TNF} \alpha$-induced cancer cell migration and invasion in vitro but also suppresses LPS-mediated metastasis in vivo (49). The present study also showed that blockage of IL-1 $\beta$ and IL-18 signaling attenuated the effects of activation of NLRP3 inflammasome on the expressions of E-cadherin and Snail. In oral cancer (52) and gastric cancer (53), it is documented that IL-1 $\beta$ downregulates E-cadherin expression and upregulates Snail expression, and subsequently enhances migration and invasion. Besides IL-1 $\beta$, IL-18 also decreases the expression of E-cadherin in epithelial cells (54). Thus, IL-1 family cytokine-mediated regulation of E-cadherin and Snail may contribute to the A549 cell migration induced by activated NLRP3 inflammasome.

The final purpose of experimental research is to provide useful information for the clinical application. Literature shows that caspase-1 inhibitor, IL-1Ra and IL-18BP, which inhibit the NLRP3 inflammasome, are used in the clinical or in animal model research. For instance, the human recombinant IL1ra (hrIL1ra) has been used in phase II or III randomized control trial for stroke, severe sepsis and traumatic brain injury (55). The caspase- 1 inhibitor ameliorates experimental autoimmune myasthenia gravis by innate DC IL-1-IL-17 pathway (56). IL-18BP ameliorates cardiac ischemia/reperfusion injury in a murine model (57). There are two limitations in our present study: firstly, the study was conducted only in one cell line; some data in other cell lines would be more powerful to verify the conclusion. Secondly, this study was conducted in vitro, however, we plan further experiments in vivo to confirm our results to supply more valuable information for the translational application.

In conclusion, our data show that NLRP3 inflammasome activation can accelerate the proliferation and migration of A549 lung cancer cells by releasing IL-1 $\beta$ and IL-18 in an autocrine or paracrine manner. These results suggests that molecules participating in NLRP3 inflammasome signaling may be promising therapeutic targets for the treatment of lung adenocarcinoma.

\section{Acknowledgements}

This study was supported by the National Natural Science Foundation of China (NSFC) under grant 81273571, the National Technological Special Project for 'Significant New Drugs Development' (2011ZX09302-003-02), a Jiangsu Clinical Research Center for Respiratory Diseases project under grant BL2012012 and a project funded by the Priority Academic Program Development of Jiangsu Higher Education Institutions (PAPD).

\section{References}

1. Siegel R, Ma J, Zou Z and Jemal A: Cancer statistics, 2014. CA Cancer J Clin 64: 9-29, 2014.

2. Tarassishin L, Casper D and Lee SC: Aberrant expression of interleukin- $1 \beta$ and inflammasome activation in human malignant gliomas. PLoS One 9: e103432, 2014.

3. Landskron G, De la Fuente M, Thuwajit P, Thuwajit $C$ and Hermoso MA: Chronic inflammation and cytokines in the tumor microenvironment. J Immunol Res 2014: 149185, 2014.

4. Coussens LM and Werb Z: Inflammation and cancer. Nature 420: 860-867, 2002.

5. Mantovani A: Cancer: Inflaming metastasis. Nature 457: 36-37, 2009.

6. Ozaki E, Campbell M and Doyle SL: Targeting the NLRP3 inflammasome in chronic inflammatory diseases: Current perspectives. J Inflamm Res 8: 15-27, 2015.

7. Kolb R, Liu GH, Janowski AM, Sutterwala FS and Zhang W: Inflammasomes in cancer: A double-edged sword. Protein Cell 5: $12-20,2014$.

8. Okamoto M, Liu W, Luo Y, Tanaka A, Cai X, Norris DA, Dinarello CA and Fujita M: Constitutively active inflammasome in human melanoma cells mediating autoinflammation via caspase-1 processing and secretion of interleukin-1beta. J Biol Chem 285: 6477-6488, 2010.

9. Zhu Z, Zhong S and Shen Z: Targeting the inflammatory pathways to enhance chemotherapy of cancer. Cancer Biol Ther 12: 95-105, 2011

10. Meng XF, Wang XL, Tian XJ, Yang ZH, Chu GP, Zhang J, Li M, Shi J and Zhang C: Nod-like receptor protein 1 inflammasome mediates neuron injury under high glucose. Mol Neurobiol 49: 673-684, 2014.

11. Fortin CF, Ear T and McDonald PP: Autocrine role of endogenous interleukin-18 on inflammatory cytokine generation by human neutrophils. FASEB J 23: 194-203, 2009.

12. Rivollier A, Mazzorana M, Tebib J, Piperno M, Aitsiselmi T, Rabourdin-Combe C, Jurdic P and Servet-Delprat C: Immature dendritic cell transdifferentiation into osteoclasts: A novel pathway sustained by the rheumatoid arthritis microenvironment. Blood 104: 4029-4037, 2004.

13. Yu Y, Arora A, Min W, Roifman CM and Grunebaum E: EdU incorporation is an alternative non-radioactive assay to $[(3) \mathrm{H}]$ thymidine uptake for in vitro measurement of mice T-cell proliferations. J Immunol Methods 350: 29-35, 2009. 
14. Livak KJ and Schmittgen TD: Analysis of relative gene expression data using real-time quantitative PCR and the 2(-Delta Delta C(T)) method. Methods 25: 402-408, 2001.

15. Tania M, Khan MA and Fu J: Epithelial to mesenchymal transition inducing transcription factors and metastatic cancer. Tumour Biol 35: 7335-7342, 2014

16. Zitvogel L, Kepp O, Galluzzi L and Kroemer G: Inflammasomes in carcinogenesis and anticancer immune responses. Nat Immunol 13: 343-351, 2012.

17. Janowski AM, Kolb R, Zhang W and Sutterwala FS: Beneficial and Detrimental Roles of NLRs in Carcinogenesis. Front Immunol 4: 370, 2013.

18. Strowig T,Henao-Mejia J, Elinav E and Flavell R: Inflammasomes in health and disease. Nature 481: 278-286, 2012.

19. Allen IC, TeKippe EM, Woodford RM, Uronis JM, Holl EK, Rogers AB, Herfarth HH, Jobin C and Ting JP: The NLRP3 inflammasome functions as a negative regulator of tumorigenesis during colitis-associated cancer. J Exp Med 207: 1045-1056, 2010.

20. Zhang A, Wang P, Ma X, Yin X, Li J, Wang H, Jiang W, Jia Q and Ni L: Mechanisms that lead to the regulation of NLRP3 inflammasome expression and activation in human dental pulp fibroblasts. Mol Immunol 66: 253-262, 2015.

21. Sagulenko V, Thygesen SJ, Sester DP, Idris A, Cridland JA Vajihala PR, Roberts TL, Schroder K, Vince JE, Hill JM, et al: AIM2 and NLRP3 inflammasomes activate both apoptotic and pyroptotic death pathways via ASC. Cell Death Differ 20: 1149-1160, 2013

22. Maelfait J, Vercammen E, Janssens S, Schotte P, Haegman M Magez S and Beyaert R: Stimulation of Toll-like receptor 3 and 4 induces interleukin-1beta maturation by caspase- 8 . J Exp Med 205: 1967-1973, 2008

23. Antonopoulos C, El Sanadi C, Kaiser WJ, Mocarski ES and Dubyak GR: Proapoptotic chemotherapeutic drugs induce noncanonical processing and release of IL-1beta via caspase- 8 in dendritic cells. J Immunol 191: 4789-4803, 2013.

24. Gringhuis SI, Kaptein TM, Wevers BA, Theelen B, van der Vlist M, Boekhout T and Geijtenbeek TB: Dectin-1 is an extracellular pathogen sensor for the induction and processing of IL-1 $\beta$ via a noncanonical caspase- 8 inflammasome. Nat Immunol 13: 246-254, 2012.

25. Li S, Sun R, Chen Y, Wei H and Tian Z: TLR2 controls the development of hepatocellular carcinoma by reducing interleukin-18-mediated immunosuppression. Cancer Res, Jan. 19, 2015 (Epub ahead of print). doi: 10.1158/0008-5472. CAN-14-2371.

26. Saijo Y, Tanaka M, Miki M, Usui K, Suzuki T, Maemondo M, Hong X, Tazawa R, Kikuchi T, Matsushima K, et al: Proinflammatory cytokine IL-1 beta promotes tumor growth of Lewis lung carcinoma by induction of angiogenic factors: In vivo analysis of tumor-stromal interaction. J Immunol 169: 469-475, 2002.

27. Wang L, Zhang LF, Wu J, Xu SJ, Xu YY, Li D, Lou JT and Liu MF: IL-1 $\beta$-mediated repression of microRNA-101 is crucial for inflammation-promoted lung tumorigenesis. Cancer Res 74 4720-4730, 2014.

28. Fabbi M, Carbotti G and Ferrini S: Context-dependent role of IL-18 in cancer biology and counter-regulation by IL-18BP. J Leukoc Biol 97: 665-675, 2015.

29. Rovina N, Hillas G, Dima E, Vlastos F, Loukides S, Veldekis D, Roussos C, Alhanatis M and Bakakos P: VEGF and IL-18 in induced sputum of lung cancer patients. Cytokine 54: 277-281, 2011.

30. Kim KE, Song H, Hahm C, Yoon SY, Park S, Lee HR, Hur DY, Kim T, Kim CH, Bang SI, et al: Expression of ADAM33 is a novel regulatory mechanism in IL-18-secreted process in gastric cancer. J Immunol 182: 3548-3555, 2009.

31. Kim KE, Song H, Kim TS, Yoon D, Kim CW, Bang SI, Hur DY, Park $\mathrm{H}$ and Cho DH: Interleukin-18 is a critical factor for vascular endothelial growth factor-enhanced migration in human gastric cancer cell lines. Oncogene 26: 1468-1476, 2007.

32. Kim J, Kim C, Kim TS, Bang SI, Yang Y, Park H and Cho D IL-18 enhances thrombospondin-1 production in human gastric cancer via JNK pathway. Biochem Biophys Res Commun 344: 1284-1289, 2006.

33. Vidal-Vanaclocha F, Fantuzzi G, Mendoza L, Fuentes AM, Anasagasti MJ, Martín J, Carrascal T, Walsh P, Reznikov LL, Kim SH, et al: IL-18 regulates IL-1beta-dependent hepatic melanoma metastasis via vascular cell adhesion molecule-1. Proc Natl Acad Sci USA 97: 734-739, 2000.
34. Apte RN, Dotan S, Elkabets M, White MR, Reich E, Carmi Y, Song X, Dvozkin T, Krelin Y and Voronov E: The involvement of IL-1 in tumorigenesis, tumor invasiveness, metastasis and tumorhost interactions. Cancer Metastasis Rev 25: 387-408, 2006

35. Martín MJ, Calvo N, de Boland AR and Gentili C: Molecular mechanisms associated with PTHrP-induced proliferation of colon cancer cells. J Cell Biochem 115: 2133-2145, 2014.

36. Will M, Qin AC, Toy W, Yao Z, Rodrik-Outmezguine V, Schneider C, Huang X, Monian P, Jiang X, de Stanchina E, et al: Rapid induction of apoptosis by PI3K inhibitors is dependent upon their transient inhibition of RAS-ERK signaling. Cancer Discov 4: 334-347, 2014.

37. Johannessen $\mathrm{M}$ and Moens U: Multisite phosphorylation of the cAMP response element-binding protein (CREB) by a diversity of protein kinases. Front Biosci 12: 1814-1832, 2007.

38. Reddy VS, Valente AJ, Delafontaine P and Chandrasekar B: Interleukin-18/WNT1-inducible signaling pathway protein-1 signaling mediates human saphenous vein smooth muscle cell proliferation. J Cell Physiol 226: 3303-3315, 2011.

39. Hosotani Y, Kashiwamura S, Kimura-Shimmyo A, Sekiyama A, Ueda H, Ikeda T, Mimura O and Okamura H: Interleukin-18 prevents apoptosis via PI3K/Akt pathway in normal human keratinocytes. J Dermatol 35: 514-524, 2008.

40. Fix C, Bingham K and Carver W: Effects of interleukin-18 on cardiac fibroblast function and gene expression. Cytokine 53: 19-28, 2011.

41. Yang KY, Bae WS, Kim MJ, Bae YC, Kim YJ, Kim HJ, Nam SH and Ahn DK: Participation of the central p38 and ERK1/2 pathways in IL-1 $\beta$-induced sensitization of nociception in rats. Prog Neuropsychopharmacol Biol Psychiatry 46: 98-104, 2013.

42. Venkatesan B, Valente AJ, Reddy VS, Siwik DA and Chandrasekar B: Resveratrol blocks interleukin-18-EMMPRIN cross-regulation and smooth muscle cell migration. Am J Physiol Heart Circ Physiol 297: H874-H886, 2009.

43. Chang MC, Hung HP, Lin LD, Shyu YC, Wang TM, Lin HJ, Chan CP, Huang CC and Jeng JH: Effect of interleukin-1 $\beta$ on ICAM-1 expression of dental pulp cells: Role of PI3K/Akt, MEK/ERK, and cyclooxygenase. Clin Oral Investig 19: 117-126, 2015.

44. Yan B, Zhang W, Jiang LY, Qin WX and Wang X: Reduced E-cadherin expression is a prognostic biomarker of non-small cell lung cancer: A meta-analysis based on 2395 subjects. Int J Clin Exp Med 7: 4352-4356, 2014

45. Wang R, Ke ZF, Wang F, Zhang WH, Wang YF, Li SH and Wang LT: GOLPH3 overexpression is closely correlated with poor prognosis in human non-small cell lung cancer and mediates its metastasis through upregulating MMP-2 and MMP-9. Cell Physiol Biochem 35: 969-982, 2015.

46. Fiorentini C, Bodei S, Bedussi F, Fragni M, Bonini SA, Simeone C, Zani D, Berruti A, Missale C, Memo M, et al: GPNMB/OA protein increases the invasiveness of human metastatic prostate cancer cell lines DU145 and PC3 through MMP-2 and MMP-9 activity. Exp Cell Res 323: 100-111, 2014.

47. Bandapalli OR, Ehrmann F, Ehemann V, Gaida M, MacherGoeppinger S, Wente M, Schirmacher $\mathrm{P}$ and Brand $\mathrm{K}$ : Down-regulation of CXCL1 inhibits tumor growth in colorectal liver metastasis. Cytokine 57: 46-53, 2012.

48. Gogali A, Charalabopoulos K, Zampira I, Konstantinidis AK, Tachmazoglou F, Daskalopoulos G, Constantopoulos SH and Dalavanga Y: Soluble adhesion molecules E-cadherin, intercellular adhesion molecule-1, and E-selectin as lung cancer biomarkers. Chest 138: 1173-1179, 2010.

49. Wu Y and Zhou BP: Inflammation: A driving force speeds cancer metastasis. Cell Cycle 8: 3267-3273, 2009.

50. Kase S, Sugio K, Yamazaki K, Okamoto T, Yano $\mathrm{T}$ and Sugimachi K: Expression of E-cadherin and beta-catenin in human non-small cell lung cancer and the clinical significance. Clin Cancer Res 6: 4789-4796, 2000.

51. Grant JL, Fishbein MC, Hong LS, Krysan K, Minna JD, Shay JW, Walser TC and Dubinett SM: A novel molecular pathway for Snail-dependent, SPARC-mediated invasion in non-small cell lung cancer pathogenesis. Cancer Prev Res (Phila) 7: 150-160, 2014.

52. Lee CH, Chang JS, Syu SH, Wong TS, Chan JY, Tang YC, Yang ZP, Yang WC, Chen CT, Lu SC, et al: IL-1 $\beta$ promotes malignant transformation and tumor aggressiveness in oral cancer. J Cell Physiol 230: 875-884, 2015.

53. Jee YS, Jang TJ and Jung KH: Prostaglandin E(2) and interleukin-1 $\beta$ reduce E-cadherin expression by enhancing snail expression in gastric cancer cells. J Korean Med Sci 27: 987-992, 2012. 
54. Bani-Hani AH, Leslie JA, Asanuma H, Dinarello CA Campbell MT, Meldrum DR, Zhang H, Hile K and Meldrum KK IL-18 neutralization ameliorates obstruction-induced epithelialmesenchymal transition and renal fibrosis. Kidney Int 76: 500-511, 2009.

55. Helmy A, Guilfoyle MR, Carpenter KLH, Pickard JD, Menon DK and Hutchinson PJ: Recombinant human interleukin-1 receptor antagonist in severe traumatic brain injury: A phase II randomized control trial. J Cereb Blood Flow Metab 34: 845-851, 2014
56. Wang CC, Li H, Zhang M, Li XL, Yue LT, Zhang P, Zhao Y, Wang S, Duan RN, Li YB, et al: Caspase-1 inhibitor ameliorates experimental autoimmune myasthenia gravis by innate dendric cell IL-1-IL-17 pathway. J Neuroinflammation 12: 118, 2015.

57. Gu H, Xie M, Xu L, Zheng X, Yang Y and Lv X: The protective role of interleukin-18 binding protein in a murine model of cardiac ischemia/reperfusion injury. Transpl Int 28: 1436-1444, 2015. 